\title{
PROCESS BASED NUMERICAL MODELING AND LABORATORY EXPERIMENTS ON THE MORPHOLOGICAL CHANGE OF COASTAL SAND DUNE
}

\author{
Sungwon Shin, Hanyang University, sungwshin@hanyang.ac.kr \\ Kideok Do, Korea Maritime and Ocean University, kddo@kmou.ac.kr \\ Daniel Cox, Oregon State University, dan.cox@oregonstate.edu
}

\section{INSTORUCTION}

Coastal sand dunes are important in the nearshore environment with respect to the sand supply, ecosystem, and hazard mitigation. While the reliable prediction of the dune erosion is important, numerical modeling of this phenomenon is still challenging.

In this study, a process based morphological modeling was performed and the results were compared with largescale laboratory experimental data.

\section{LARGE_SCALE LABORATORY EXPERIMENTS}

In this study, a process based morphological modeling was performed and the results were compared with largescale laboratory experimental data.

Two-dimensional large-scale laboratory experiments were conducted with 1:6 geometric scale in the wave flume $(104 \mathrm{~m}(\mathrm{~L}) \times 3.7 \mathrm{~m}(\mathrm{~W}) \times 4.6 \mathrm{~m}(\mathrm{D}))$ of the Hinsdale Wave Research Laboratory at Oregon State University (Maddux et al, 2006) as shown in Figure 1. The flume was filled with $800 \mathrm{~m}^{3}$ of $0.2 \mathrm{~mm}$-diameter natural beach sand from the Oregon coast. An initial beach and dune profile were selected based on field observations of various dune systems on the east coast of US.

The wave conditions include pre-storm, storm, and post storm based on random wave time series (TMA, $r=3.3$ ). Cross-shore Wave heights, fluid velocities, and the profile changes of the beach and dune were measured in this test.
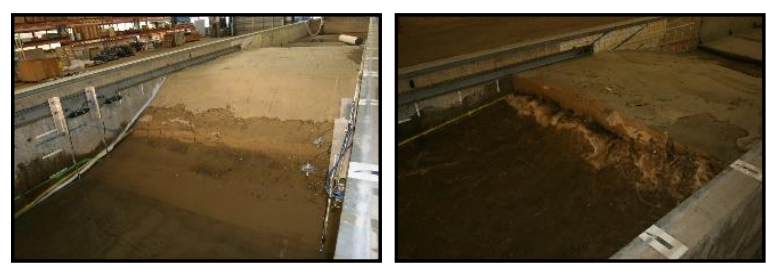

Figure 1. Dune formation and swash zone instruments (left) and dune face after the storm wave impacts (right)

\section{NUMERICAL SIMULATION}

The process based model, XBeach was applied to predict the nearshore hydrodynamics and bed level change during storm wave condition. XBeach is a twodimensional horizontal model depth-averaged model for wave propagation and has modules for simulating sediment transport and bed level change due to wave and wave-driven circulation. This model is coupled with a nonlinear shallow water equation accounting for the generation of low-frequency motions (Roelvink et al., 2009), which are important to beach and dune erosion. This study used the space varying grid to reduce computational time. The grid resolution in the crossshore direction is $0.15 \mathrm{~m}$ near the shore line, toward the seaward boundaries $\Delta \mathrm{x}$ increased to $2 \mathrm{~m}$, respectively.
A number of semi-empirical parameters are used within XBeach model to predict morphodynamic process (Roelvink et al., 2009). In this study, the numerical simulations were performed using the WTI settings as semi-empirical parameters. XBeach developers have already defined default settings for these parameters, which were re-determined by the WTI2017 (Wettelijk Toets Instrumentarium) project in order to intend for use an advanced dune safety assessment model (van Geer et al., 2015). Figure 2 shows the comparisons for measured beach profile under wave condition 4 $(\mathrm{Hs}=1.17 \mathrm{~m}, \mathrm{Tp}=4.90 \mathrm{~s}, \mathrm{WL}=4.13 \mathrm{~m})$ as an example. It was found that the default settings of XBeach model overpredicted the offshore sediment transport and dune erosion, but the results of WTI setting showed good agreement with the measured beach profile. Especially, the wave skewness (facSk) and asymmetry (facAs) gives the highest contribution to predict dune erosion and it is in agreement with previous paper of XBeach model (Roelvink et al., 2009).

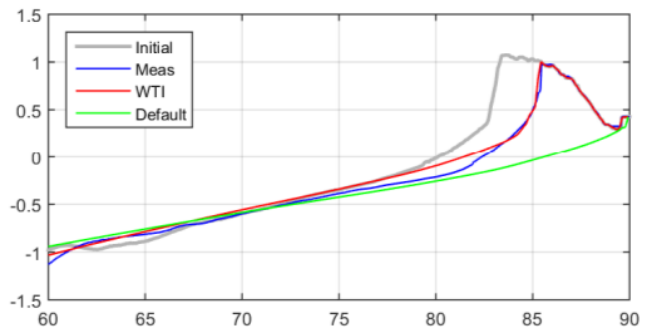

Figure 2 . Measured and simulated beach profiles under a storm wave condition $(\mathrm{Hs}=1.17 \mathrm{~m}, \mathrm{Tp}=4.90 \mathrm{~s}, \mathrm{~d}=4.13 \mathrm{~m}$ )

\section{AKNOWLEDGEMENT}

This research was partly supported by the National Research Foundation of Korea(NRF) grant funded by the Korea government (2017R1A2B4010108) and the research fund of Hanyang University(HY-2017-N). Authors are also thankful to Maddux and Ruggiero for providing their experimental data.

\section{REFERENCES}

Maddux, Ruggiero, Palmsten, Haolman and Cox (2006): Laboratory observation of dune erosion, AGU Fall Meeting, San Francisco.

Roelvink, Reniers, van Dongeren, van Thiel de, McCall and Lescinski. (2009): Modelling storm impacts on beaches, dunes and barrier islands, Coastal Engineering, ELSEVIER, Vol 56, 1133-1152.

Van Geer, Bieman, Hoonhout and Boers (2015): XBeach 1D - Probabilistic model: ADIS, Settings, Model uncertainty and Graphical User Interface. Tec. Rep 1209436-002-HYE-0001, Deltares, 34. 